\title{
The Shark Tank Experience: How Engineering Students Learn to Become Entrepreneurs
}

\section{Dr. Tobias Haertel, TU Dortmund University}

Tobias Haertel studied social sciences and put his research focus on science and technology studies as well as creativity in higher engineering education. In his work, he always tries to combine the depth and sophisticated spirit of the analogue world with the interconnectedness and usability of digital techniques.

\section{Mr. Claudius Terkowsky, TU Dortmund University}

Since 2009, he is senior researcher, lecturer and trainer in higher engineering education. Since 2012, he is scientific lead of the "Engineering Education Research Group" at the Center for Higher Education / TU Dortmund University. He holds a degree in education and works for many years in engineering education research, higher education research, and science and technology studies. His current research fields are: teaching and learning in the engineering lab; fostering creativity in engineering; digital media in higher education and vocational training; engineering education cultures.

\section{Mr. Dominik May, TU Dortmund University}

Dominik May holds a degree in Industrial Engineering from TU Dortmund University (Germany). Currently he is a research associate and doctoral candidate at the Center for Higher Education at TU Dortmund University in the area of engineering education research. In his position he is managing several research and development projects on engineering education and technical training. Furthermore he offers workshops on professional teaching and learning for engineering faculty. In his research Dominik May focuses, inter alia, on future requirements for science and engineering graduates, such as international competence, in order to become successful engineers in a globalized professional world. Therefore he designs and investigates respective educational strategies with a special focus on online solutions and the integration of remote laboratories. For his research and the development of several transnational online courses he benefits from his working experience in international companies and a broad international professional network. Furthermore Dominik May is founding member of both the Engineering Education Research Group at the Center for Higher Education and the Working Group for Engineering Education at the German Society for Higher Education (dghd). 


\title{
The Shark Tank Experience: How Engineering Students Learn to Become Entrepreneurs
}

\author{
Tobias Haertel, TU Dortmund University, Germany \\ Claudius Terkowsky, TU Dortmund University, Germany \\ Dominik May, TU Dortmund University, Germany
}

\begin{abstract}
How can students learn to think like an entrepreneur, boost their creativity and aim at innovative success? Fostering creativity and entrepreneurship is not only a question of knowledge transfer, but has a lot to do with working with students' personality, attitudes and-most importantcourage. The research project "ELLI - Excellence in Teaching and Learning in Higher Engineering Education" funded by the German Federal Ministry of Education and Research is focusing these questions and has developed a course concept that fosters engineering students' creativity and entrepreneurial thinking. Based on the well-known television show "shark tank", students have to generate ideas for successful start-up enterprises and prepare a pitch that is creative and personally convincing. Furthermore, students are asked to do "something unusual". In this paper, we want to present the results and experiences made in the first two terms with this course concept. By applying the Business Model Canvas, the students were able to gain knowledge about designing of business models in particular and entrepreneurship in general. However, surprisingly, students showed difficulties in taking risks-even in the playful simulation of the pitches. They tried to avoid uncertainty, which is essential for being creative or being an entrepreneur. As a possible reason, the influence of engineering education at all is discussed.
\end{abstract}

\section{Introduction}

Fortunately, the discussions about the quality and importance of engineering education in a globalized world that faces tremendous challenges has been gaining momentum in the last decade. Currently, two subtopics of engineering education come more and more into focus: Creativity $^{1}$ and Entrepreneurship ${ }^{2,3}$ :

- creativity in order to strengthen engineers' abilities to generate ideas, to find optimal solutions for complex problems, and to invent new processes and products

- entrepreneurship in order to transform these processes and products into business models, and finally into innovation

Only if creative ideas become innovations, they are able to unfold impact and start to be useful. Engineers need entrepreneurship skills, and thus, entrepreneurship education for engineering students has become more and more important in recent years. They need to "understand and contribute in the context of market and business pressures." ${ }^{\text {"F }}$ Furthermore, entrepreneurship skills are relevant for career success; students with these skills are expected to be better prepared to support their employers as innovators, act as managers and competent team workers ${ }^{4}$. This raises three essential questions:

1. What is and what means creativity and entrepreneurship in engineering contexts?

2. What are the implications for engineering education? 
3. Are creativity and entrepreneurial thinking competences which can be learned by students, or are they a result of a life-long socializing process that cannot be influenced, at least not in the small period of an engineering seminar?

These questions will be followed in the next section ("Creativity and Entrepreneurship in Engineering"). Based on the answers, a concept for an entrepreneurship seminar will be presented in the third section ("The shark tank experience"). Bringing engineering and economics students together, this seminar (respectively its tutorial) aims to foster their corresponding skills, or, with other words, their abilities to invent, to decide, to convince, and finally to sell. This seminar was hold twice, with smaller adjustments for improvement after the first pass. Applying creativity techniques as well as the task to "do something unusual" and finally preparing a pitch in front of potential investors were central elements of the tutorials. In section 4 ("Findings"), the results collected in the tutorials are discussed. Possible reasons why some learning outcomes could be reached while others failed are reflected. The paper ends with a conclusion.

\section{Creativity and Entrepreneurship in Engineering}

Creativity is an essential element of $21^{\text {st }}$ century life ${ }^{5}$. For Cropley \& Cropley ${ }^{6}$, the sputnik shock was a starting point for broad discussions about creativity in western societies. Creativity was seen as a key to catch up with the technology advantage of the Russians, as it had become obvious by the successful satellite mission and its worldwide receivable beeping. Therefore, Western countries made substantial efforts to promote the creativity of its engineers.

However, up to now for many leaders, managers, practitioners and educators creativity is still a blind $\operatorname{spot}^{6}$. Either, they do not attach importance to creativity, or they do not have manageable concepts of what creativity is and how it can be fostered.

Baillie says "it is however not clear how creativity can be nurtured or fostered in students or how it can be assessed. What is creativity? What blocks it and what facilitates it?" 7 . Scientist such as Guilford ${ }^{8}$ had already discovered a link between creativity, engineering and technology before the sputnik was sent to orbit. He established the distinction between divergent thinking (generating alternatives, seeing multiple possibilities to solve a problem) and convergent thinking (single, well established answer to a problem) as basic elements of creative processes. Since then, this rather simple concept of creativity has been elaborated by many scientists from different disciplines like psychology, philosophy, social sciences and economics. A vast mass of definitions and approaches have been developed, and in all their diversity, they do not necessarily facilitate a clear understanding of creativity ${ }^{9}$. Summarizing a lot of relevant work in this field, Plucker, Beghetto \& Dow ${ }^{10}$ define that creativity is "the interaction among aptitude, process and environment by which an individual or group produces a perceptible product that is both novel and useful as defined within a social context". Based on this basic definition, Cropley ${ }^{5}$ transfers important results of the broader discussion about creativity into the context of engineering. Focusing on problem solving, an essential part of engineers' activities, he develops several concepts of creativity, which leads him to the question, whether engineers can learn to be creative. 
Table 1: Short-term and long-term learning outcomes

\begin{tabular}{|c|c|c|}
\hline & $\begin{array}{l}\text { Can be learned in foreseeable } \\
\text { amount of time (short-term) }\end{array}$ & $\begin{array}{l}\text { Long-term learning process, } \\
\text { influenced by socialization }\end{array}$ \\
\hline Creativity & $\begin{array}{l}\text { - Applying creativity techniques } \\
\text { for divergent thinking } \\
\text { processes } \\
\text { - Reflect and improve (or if not } \\
\text { possible adapt to) } \\
\text { environmental aspects }\end{array}$ & $\begin{array}{l}\text { - Unprejudiced thinking and } \\
\text { openness for new ideas and } \\
\text { change in general (PMI, AMA) } \\
\text { - Self-confidence and courage to } \\
\text { create, to do something unusual, } \\
\text { to navigate in open systems, } \\
\text { non-conformist behavior } \\
\text { - Spirit of research: Being } \\
\text { curious and motivated to follow } \\
\text { own ideas and generate new } \\
\text { knowledge, to become a } \\
\text { valuable part of the scientific } \\
\text { community }\end{array}$ \\
\hline Entrepreneurship & $\begin{array}{l}\text { Knowledge about } \\
\text { management methods, how to } \\
\text { write business plans and get } \\
\text { financing, instruments to } \\
\text { protect intellectual properties } \\
\text { - Knowledge about product } \\
\text { design and development, } \\
\text { prototyping, technology } \\
\text { trends, and market analysis. }\end{array}$ & 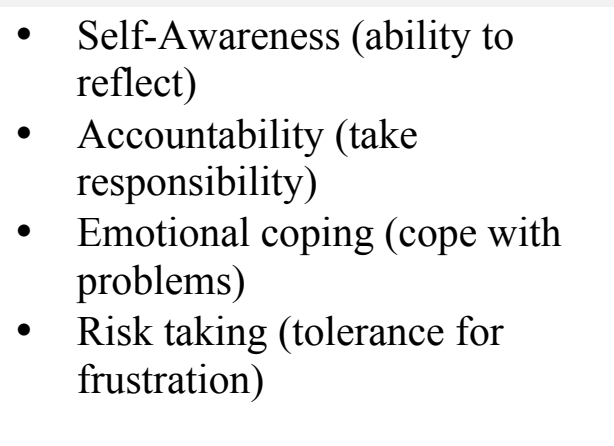 \\
\hline
\end{tabular}

Nowadays, the opinion that creativity can be learned is widely accepted. In varying degrees and focal points, some authors ${ }^{11,12,13,14,15}$ state that at least some aspects of creativity can be learned. Cropley ${ }^{5}$ divides these approaches into those which focus on generating ideas (process, environment, product) and work regarding a person's creative habit. While the first ones describe techniques and methods that can be learned within a foreseeable amount of time, the latter aspect is rather connected with socialization.

The differences are shown in table 1. Childhood experiences, in which idea generation is rewarded, have a great impact on developing a creative habit ${ }^{16,17}$. For May ${ }^{18}$, courage to create is the essence of creativity. In his opinion, creativity is the process of making and bringing something new into being. So, he puts the focus on realizing ideas in the literal sense of creating. The newer, the more original, the crazier the idea, the more courage is needed to communicate and defend it, to realize it against the risk of rejection. Bertram \& Preißing ${ }^{19}$ call it "navigating in open systems.", which is inherent to all creative actions. Routines and traditions give the feeling of safety; they allow a safe navigation along paths of known expectations, and staying on them means not fear criticism or negative feedback: "Laws, rules, regulations, conventions and taboos reduce complexity and create a relatively safe frame for a peaceful, organized life and coexistence." "By this, "closed systems" that bring about inner safety are constituted. However, creativity means to leave this closed system and strike off into a new closed system. Being 
creative means to inevitably leave the closed system with all its well-known routines, traditions and norms for a while. For the moment of transition, the creative person is in an "open system" in which others expectations and reactions are unknown: "In the moment of transition from one closed system to another one appears a temporary open system, an exposed position that contains risks and accordingly is frightening." $" 19$

To be aware and orientate oneself towards the expectations of others is a habit that children learn between the age of three and a half and four ${ }^{20}$. From this point on, environment's reaction on conformity or self-direction influence the children's further development regarding their behavior to meet or disappoint others expectations, although this is only one (important) factor besides others ${ }^{21}$. On the other hand, although childhood experiences have an impact, according to Hoffmann ${ }^{22}$, even grown-ups can learn courage . But it needs time to learn behaving courageous and showing self-confidence, a lot small steps have to be climbed.

Another creative habit that can be learned is what Haertel, Terkowsky \& Jahnke call the "spirit of research". Universities can provide a learning culture to their engineering students that is characterized by instructional learning, repetitions and even predefined topics for master theses. Under such conditions, it is rather unlikely that interest in research topics is generated, that students develop their own research questions and motivation to answer them. In order to foster such a "spirit of research", students should get in contact with actual research questions as often as possible in their studies; they should be allowed to learn on their own, to follow their interest, to experiment and even to fail, to get in contact with researchers and become a part of the scientific community.

Summarized, different approaches put their focus on different aspect of creativity, and they also differ in the scope of possible learning outcomes. While some learning objectives can be reached in the short term (like generating ideas with the help of creativity techniques), others need more time to be learned (like navigating in open systems, see table 1). This is an important insight for the didactical design: Not all aspects of creativity can be learned within the period of one semester, one seminar. If creativity is understood as a complex competence, consisting of knowledge about idea generation, a creative habitus and the agency to create, it needs more time than one semester to be acquired. Regarding the didactical design, only the short-term learning outcomes (table 1) can be reached effectively. Nevertheless, a good didactical concept of creativity should at least trigger the long-term oriented learning objectives.

As shown in table 1, similar conclusions can be observed when looking at entrepreneurship. Some contributions emphasize the importance of knowledge about management, business plans, financing and intellectual property (e.g. ${ }^{23,24,25}$ ) or a "solid experience in product design and development, prototyping, technology trends, and market analysis" ${ }^{26}$. These topics can be learned in a foreseeable amount of time. However, as in the creativity discussion, May et al. ${ }^{3}$ ask whether "entrepreneurship is an innate ability, or a skill that can be acquired through education." From his point of view, society significantly influences the willingness to become entrepreneur. Cultures that value entrepreneurship have more entrepreneurs than societies in which entrepreneurship is not fostered or even valued. This indicates that the environment influences entrepreneurial behavior at least to a certain degree ${ }^{3}$. Belotti et al. ${ }^{26}$ define entrepreneurship as "a personal skill and motivation that draws a person to engage his abilities and efforts in the creation of new products and service." For them, personal skills in this relation are self- 
Table 2: Two tasks in the tutorial

Task 1: Shark Tank

- A group of entrepreneurs have a pitch in front of investors. With a short presentation, they have to convince the investors to invest in their business idea.

- In return for their investment, investors get a share in the company.

- A pitch must not be longer than 5 minutes. After that, the investors have time to ask questions, i.e., about the business plan, sales figures, prior actions etc.

- If interested, one or more investors submits an offer.

- Entrepreneurs have to decide whether they accept the offer or not.
Task 2: Do something unusual

- Not in the sense of a 'test of courage', but as an encouragement to overcome challenging difficult social situations: "Leave the comfort zone of safe terrains of normative regulative social routines and traditions! Go against something you for yourself have declared as a social interaction norm!"

- No idea for solving this task is too "unspectacular", no solution is wrong, since norms are understood and sensed in a different, subjective way. Each participant has to find an individual solution for this task along his very own norms, avoiding mental overload.

- Students have to observe themselves when they perform their solution.

- Finally, students have to reflect what happened to and with them.

awareness, accountability, emotional coping, creativity and risk taking. But these skills are at least to some extend influenced by socialization processes as well and cannot be learned in a short period of time.

Engineering education, which wants to foster creativity and entrepreneurial thinking, has to put these aspects into account. In the following section, a learning scenario that considers these insights is presented.

\section{The shark tank experience}

At the medium sized German Technical University Dortmund, a professor at the faculty of economics and the ELLI engineering education research project collaborated for fostering students' entrepreneurial skills. While the economics professor was responsible for the seminar and theoretical background, the scientists working in the project took the practical part covered by the tutorials. The entrepreneurship seminar was part of the master studies "innovation management" in the faculty of economics, but it was opened for engineering students as well. Engineering students were invited via university's email system. Surprisingly, in both terms about half of the students were engineering students, the others studied economics, but had entered university with different bachelor degrees such as cultural management or health management.

The first seminar was held in summer term 2015 with 12 students, the second in winter term 2015/2016 with 8 students, 2 of them Erasmus students from Poland. The first seminar was about entrepreneurship in the fields of nanotechnology and biotechnology. The second seminar focused on academic entrepreneurship. Both seminars were accompanied by a tutorial which aimed to 
take a practical part. The scope of the tutorials was limited to the short-term learning objectives applying creativity techniques, reflecting creativity and environmental aspects as well as knowledge about business plans and how to get financing. In reference to the long-term objectives, risk taking, navigating in open systems and the courage to create should be triggered. The tutorial took place all-day on two consecutive days. While a first task (task 1, see table 2) addresses both, the short-term and long-term objectives, a second task was implemented to especially trigger learning processes that need more time (risk-taking, navigating in open systems).

Elements of the first tutorial in summer 2015 were:

- Students should learn basic facts about creativity and reflect upon their own creativity in order to work out an individual concept of creativity.

- Students should develop a business idea, either in the seminar's context (nanotechnology and biotechnology) or in any other field they were interested in. They did not need to get rich, but they had to ensure that they made their living with their business.

- With the help of creativity techniques, students should develop a creative pitch for their business idea. The pitch followed the rules of the well-known television show "Shark Tank" (see table 2, task 1).

- Students should do something unusual (see table 2, task 2).

- Students were graded for the tutorial, which was $20 \%$ of the seminar's overall grading. They were told that not the quantity or quality of their ideas were graded, but their willingness to participate and openness for the methods and tasks.

Task1: The 12 students were divided into 3 groups with 4 students each. Each student had to develop an own business idea and prepare a pitch, always supported by the other 3 students. But only supported, the presenting student had the right to make all decisions and was responsible for the success or failure of the pitch. So it was teamwork with a hierarchy. 4 "creative rounds" ensured that each student had the opportunity to play the "entrepreneur" role. Each round contained 4 phases:

- A divergent thinking phase (30 minutes) by using varying creativity techniques in order to elaborate an initial business idea and generate ideas for a successful pitch

○ Round 1: Classic brainstorming

○ Round 2: 4 Thinking Hats

○ Round 3: Force fit with pictures

○ Round 4: 6-3-5

- A convergent thinking phase (30 minutes) in which students had to decide for the most promising ideas and prepare the pitch

- A pitch phase (5 minutes presentation, 5 minutes discussion)

- A reflection phase on the pitch (factors of success or failure) and the applied creativity technique (advantages/disadvantages)

Task2: Between the first and the second day, students had to do something unusual and reflect the situation and their feelings. Here, they were not allowed to work in groups but had to find individual solutions. The same unusual-task for every participant would lead to a comparability of mastering it but it would also contain the danger of demanding too little or-even worse-too 
much of individual participants. Based on the students' reflections, this task was discussed at the beginning of the second day.

In the second pass in winter term 2015/16, some changes have been made: Again, it was an allday tutorial for two consecutive days, and students had to perform the task "do something unusual". However, the shark tank task was enhanced by using the "Business Model Canvas"28. The Business Model Canvas is a creative technique for developing a basic business model that focuses on the most important parts. Instead of a classic business plan with about 30 pages, a pin board or large peace of paper is sectioned in 9 relevant parts which are filled with sticky notes. The pitch was then based on students' findings with the Business Modell Canvas. Besides, students were completely free with the choice of their business idea. However, they were encouraged to generate a business idea which is linked to their subject of study. In the second pass, students developed business ideas in groups of two, supported by all other students in the divergent thinking phase.

At the end of each tutorial, students had time to give oral feedback about their learning experiences, what they liked and what they would like to be improved.

\section{Findings}

Task 1: Shark Tank-Students used the task to test themselves in different roles. Generally, students' ideas were based on idealism, most ideas in the first pass and all ideas in the second phase. Students wanted to make the world a better place, sustainability and social responsibility were very important to them. On the other hand, they had great difficulties designing their business ideas in a way that they would earn money. So in the pitch, entrepreneurs with idealistic ideas and an underestimation of the importance of money meet sharks who have the only intention to make money. This clash led to lively pitches and profound learning experiences. As they students in the feedback phase, they liked to experience both perspectives, entrepreneurs and investors. Students who started to play the "sharks" said they had an advantage because they already knew what is important from the investors' perspective, so that they were able to adjust their pitch when it came to them to play the entrepreneur. Students said, from the entrepreneurs' perspective, it was very hard to be criticized. They somehow identified with their ideas. So, investors' critique on their ideas was taken personally. But they also stated that, at the end of the tutorial, they would never again underestimate the importance of money.

Idealistic is one characterization of the developed and presented ideas, down-to-earth is another. Although encouraged to be creative and visionary, students avoided to generate groundbreaking ideas. Instead, they tended to develop incremental changes to already existing ideas and concepts and hoped to find their niche of the market. They did not want to take the risk of bringing something completely new into market. Logically, the contiguity to well established businesses was regularly criticized by the sharks.

Task 2: Do something unusual-Students faced this task (they had to fulfill until the next morning) mainly with curiosity. But they also mentioned some concerns that their ideas to solve the task could be too unspectacular for the other students. The task was accepted by a majority after repeating for several times that no idea is too unspectacular and no one should ask too much 
of himself or herself and at least the task is no competition but the possibility to deal with each ones' individual willingness to creativity. Consequently, the solutions varied quite strong because of the students' diverse backgrounds and personalities. For example, one student played songs in the pedestrian mall and collected money for that. Another student decided to take off his shoes and walked the long way home without wearing them, while another student went shopping in his Pajama. Yet another student dialed a phone number she did not know to overcome her fears of talking to strangers. By and large, students found a solution that fitted to their individual context despite their fears of the uncertain situation.

In the discussions, most students said that they had found a personal benefit by solving this task. When asked to describe their feelings they had before while and after solving their tasks, a typical process with individual variances could be observed: With the development of the idea and the decision to realize it emerged a stage of uneasiness that became stronger and stronger and reached its climax right before the actual realization. In the situation itself the uneasiness changed into a concentration on the situation. The own actions and the reactions of the surrounding were observed in many details. After the realization a time of relaxation and a feeling of proudness to have stood the challenge was noticed by the students.

Overall, students avoided radically solutions in both tasks, no matter what subject they study. A great amount of time of both tutorials had to be spend on working with students' willingness to take risks, even in these playful simulations and situations. Again and again, they were encouraged to take chances, think visionary, and accept periods of uncertainty. To endure uncertainty was a hard experience for most students, as they stated in the feedback phases. Furthermore, students were told repeatedly that not the quality or quantity of their ideas were graded. In order to encourage them and establish a culture that is open for entrepreneurship and creativity, most students got the best grade in the first pass and all students got the best grade in the second pass, although some of their ideas had been unsuccessful in the pitches.

Using the Business Model Canvas in the second pass made a significant improvement. It helped students to structure their pitch and focus on all relevant aspects of a business model. Although the model did not prevent students from underestimating the importance of money, it raised the discussions' level in the pitch.

The small group size has been found to be very suitable for the context. The small numbers of participating students (a maximum of 16 students would have been allowed) allowed in-depth discussions and made it possible to address and foster each student individually, similar to a coaching process. The format in the second pass, when two students had to develop a common business idea, has turned out to be more effective. Thereby, the number of pitches was reduced, so that more time could be spent on each pitch. Beyond that, the need to agree on a shared business idea fostered profound teamwork.

The context of the second seminar (academic entrepreneurship) allowed students to develop ideas closer to their context and fields of knowledge, which made them more realistic. Nano- and biotechnology as the first seminar's context made it difficult to develop realistic ideas or even assess the feasibility of ideas due to a lack of knowledge for both, students and teachers. 


\section{Discussion}

Generally, the results presented so far represent the experiences made in a tutorial that was held only twice, with a small number of students, in a very special context of a German university. What worked in this scenario will not work necessarily in other contexts, just as the observed problems might not occur in other circumstances. So the results are not representative or easily transferable, they do not constitute a study rather than a case example. During their activities, students were not surveyed systematically. But some insights might be valuable although, and they give some hints to further questions, and of course everyone is invited to use the scenario and the two tasks herself or himself and make own experiences.

First and foremost, the Shark Tank concept in combination with the Business Model Canvas has proofed very successful. It provides learning opportunities in terms of acquisition of relevant knowledge as well as personal development based on practical experiences and reflection. The roleplaying scenario was able to simulate a very crucial point in creative and entrepreneurship processes: The pitch decides on life or death of ideas, an important step from creativity to innovation. In this phase, the uncertainty is as big as can be, it is a maximum navigation in open systems.

However, students (engineering as well as economics students) surprised by avoiding radical innovations and risks even in a playful atmosphere. They managed (but also struggled with) the task to do something unusual, but only after reflecting their fears and making sure that smaller solutions are valued as well. One reason might be that, as master students, they already went through an educational phase that rewarded conformity rather than non-conformity. For engineering students, Haertel, Terkowsky \& Jahnke ${ }^{1}$ show that engineering curricula do not foster independent learning and working, multiperspective thinking or the development of original ideas. So if universities in particular and maybe societies in general do not foster nonconformity, risk-taking and endurance of uncertainty, it might not be shown on demand by students even in playful simulations.

There seems to be a paradox: To learn long-term oriented learning outcomes which are at least influenced by external factors and socializing processes, in a temporary context of a university course. There is no easy solution for this problem, and a lot of future work has still to be done. A first step is to ask students to repeat task 2, "Do something unusual", themselves regularly, and using each pass to go one small step further.

\section{Conclusion}

Why was it worth thinking about creativity and entrepreneurship in engineering education? The experience made by using the learning scenario "Shark Tank" confirms what was written before: To some extend, students can learn to become creative or an entrepreneur. But there are aspects of both entities that cannot be learned by applying a straightforward learning path under the time regime engineering education offers, such as courage, non-conformity, openness etc. It is important to have these insights in mind, if all the prominent statements about the need of engineers who change (or even maybe save) the world are serious-and not just symbolic or

political. These insights describe the bridge between knowing how to make something (generate 
ideas, design a business model) and actually making something (bringing the ideas and business models to life). Modern societies do not only need creative and entrepreneurial thinking engineers-they do also need engineers who have the courage to take risks and realize their ideas. Providing engineers with an environment which enables them to act in this way is an overall task of engineering education. Hopefully, this knowledge has not to be learned in a long-term learning process by all relevant actors in engineering education.

\section{References}

1. Tobias Haertel, Claudius Terkowsky \& Isa Jahnke (2012): Where have all the inventors gone? Is there a lack of spirit of research in engineering education? In: 15th International Conference on Interactive Collaborative Learning and 41st International Conference on Engineering Pedagogy in Villach, Proceedings, IEEE Conference Publications, pp. 1-8

2. Mary Besterfield-Sacre, Nur Ozge Ozaltin, Angela Shartrand, Larry J. Shuman, Phil Weilerstein: understanding the technical entrepreneurship landscape in engineering education, ac 2011-1729

3. Dominik May, Bengü Hosch-Dayican, Liudvika Leisyte, Lisa Sigl, Claudius Terkowsky (2015): Entrepreneurship and gender in higher engineering education in Germany. Proceedings of SEFI Annual Conference 2015. June 29 - July 2, 2015, Orléans, France

4. Aboubakr Abdeen Badawi: TVET and entrepreneurship skills. In: Revisiting global trends in TVET: Reflections on theory and practice. Published by UNESCO-UNEVOC International Centre for Technical and Vocational Education and Training, UN Campus, pp. 275-308. http://www.redetis.iipe.unesco.org/wpcontent/uploads/2013/08/2013_epub_revisiting_global_trends_in_tvet_book.pdf\#page=285

5. David H. Cropley: Creativity in Engineering: Novel Solutions to $\bar{C}$ omplex Problems

6. Cropley, A. J., \& Cropley, D. H. (2009). Fostering creativity: A diagnostic approach for education and organizations. Cresskill, NJ: Hampton Press.

7. Baillie, C. (2002). Enhancing creativity in engineering students. Engineering Science \& Education Journal, 11(5), 185-192.

8. Guilford, J. P. (1950). Creativity. American Psychologist, 5, 444-454.

9. Jahnke, Isa / Haertel, Tobias / Wildt, Johannes Wildt, 2015: Teachers' conceptions of student creativity in higher education. In: Innovations in Education and Teaching International. DOI: 10.1080/14703297.2015.1088396

10. Plucker, J. A., Beghetto, R. A., \& Dow, G. T. (2004). Why isn't creativity more important to educational psychologists? Potentials, pitfalls, and future directions in creativity research. Educational Psychologist, 39(2), 83-96.

11. Torrance, E. P. (1972). Can We Teach Children To Think Creatively? The Journal of Creative Behavior, 6(2), 114-143.

12. Amabile, T. M. (1983). The social psychology of creativity. New York, NY: Springer.

13. Richards, R., Kinney, D. K., Bennet, M., \& Merzel, A. P. C. (1988). Assessing everyday creativity: Characteristics of the Lifetime Creativity Scales and validation with three large samples. Journal of Personality and Social Psychology, 54, 476-485.

14. Runco, M. A., \& Richards, R. (Eds.). (1997). Eminent creativity, everyday creativity, and health. Greenwich, Conn: Ablex.

15. Sternberg, R. J. (2007). Creativity as a habit. In A.-G. Tan (Ed.), Creativity: A Handbook for Teachers (pp. 325). Singapore: World Scientific.

16. Kim, K. H. (2011). The creativity crisis: The decrease in creative thinking scores on the Torrance Tests of Creative Thinking. Creativity Research Journal, 23(4), 285-295.

17. Kim, K. H., \& Coxon, S. V. (2013). The Creativity Crisis, Possible Causes, and What Schools Can Do. In J. B. Jones \& L. J. Flint (Eds.), The Creative Imperative (pp. 53-68). Santa Barbara, CA: ABC-CLIO.

18. Rollo May: The Courage to Create. New York: Nortin, rev. ed., 1994.

19. U. Bertram, W. Preißing, "Navigieren im offenen System: Unternehmensführung ist ein künstlerischer Prozess,", Leonberg: Container Verl., 2007.

20. J. A. Fodor, "A theory of the cild's theory of mind," in Cognition, vol. 44, 1992, pp. 282-296.

21. S. H Schwartz, "Universals in the content and structure of values: Theory and empirical tests in 20 countries," in M. Zanna (Ed.), Advances in experimental social psychology, New York: Academic Press., vol. 25, 1992, pp. $1-65$

22. K. Hoffmann, "Die Logik des Mutes: Dein Mutmacher bist Du selbst,", 2nd ed., Springer Verl., 2013

23. Serge Luryi, Wendy Tang, Nadia Lifshitz, Gerrit Wolf, Simona Doboli, Joseph A. Betz, Peter Maritato, Yacov Shamash: Entrepreneurship in Engineering Education, http://fie-conference.org/fie2007/papers/1705.pdf

24. Steven P. Nichols, Neal E. Armstrong: Engineerin - Entrepreneurship: Does Entrepreneurship Have a Role in Engineering Education? http://ieeexplore.ieee.org/stamp/stamp.jsp?tp=\&arnumber=1189659\&tag=1 
25. M.D. Wilson, Eric Holloway, Dr. Monica Cox, \& Molly Goldstein: Entrepreneurship Education: Engineering a Pracademic Approach. ASEE Proceedings, The 2014 ASEE North Midwest Section Conference, October 1617, 2014, Iowa City, IA, http://ir.uiowa.edu/cgi/viewcontent.cgi?article=1038\&context=aseenmw2014

26. Tom Byers, Tina Seelig, Sheri Sheppard, and Phil Weilerstein: Entrepreneurship. Its Role in Engineering Education. In: THE BRIDGE. Linking Engineering and Society. National Academy of Engineering. Undergraduate Engineering Education, Vol. 43, No. 2, Summer 2013, pp. 35-40.

27. F. Bellotti, R. Berta, A. De Gloria, E. Lavagnino, F. Dagnino, M. Ott, M. Romero, M. Usart, I. S. Mayer: Designing a Course for Stimulating Entrepreneurship in Higher Education through Serious Games. Procedia Computer Science 15 (2012 ) 174 - 186. Available online: http://ac.els-cdn.com/S1877050912008319/1-s2.0S1877050912008319-main.pdf? tid=ab89195a-c906-11 e5-8a2800000aacb362\&acdnat=1454346799_9073aea0aaa606c0ec0aeb8215890a00 (2016.01.28)

28. Alexander Osterwalder, Yves Pigneur: Business Model Generation: A Handbook for Visionaries, Game Changers, and Challengers. John Wiley \& Sons, 2010. 